\title{
Tulane
}

Tulane Economics Working Paper Series

\section{Who Responds? Disentangling the Effects of Audits on Individual Tax Compliance Behavior}

\author{
James Alm \\ Tulane Economics \\ jalm@tulane.edu
}

\author{
Ali Enami \\ The University of Akron \\ aenami@uakron.edu
}

\author{
Michael McKee \\ Appalachian State University \\ mckeemj@appstate.edu
}

Working Paper 2007

September 2020

\begin{abstract}
How does individual tax compliance respond to a change in the audit rate? Most all empirical evidence suggests that an increase in the audit rate increases the compliance rate, a result that is also consistent with standard theoretical analysis of the individual compliance decision. However, this empirical evidence is typically based on estimating an average response across all taxpayers, and an average response may conceal much heterogeneity in individual responses. This paper collects individual- level data from identical laboratory experiments across five separate studies with a total of 278 student subjects that generated 8340 individual observations, in which only audit rates are varied, in order to disentangle individual responses to audit rate changes. As with most previous empirical work, our results indicate that the average response across all taxpayers is to increase (decrease) compliance when audit rates increase (decrease). However, this average response conceals enormous heterogeneity in individual responses. When the individual responses are examined in more detail, our data show that many individuals do in fact respond to higher (lower) audit rates by increasing (decreasing) their compliance. However, these individuals represent only about $2 / 3$ of all subjects. In fact, our data also show that many individuals do not respond at all to audit rate changes. Surprisingly, our data further show that some individuals actually decrease their compliance when audit rates increase, and vice versa. All of these different individual responses indicate that government policy interventions must consider the "full house" of individual behaviors when devising appropriate policies.
\end{abstract}

Keywords: Tax evasion, Tax compliance, Behavioral economics, Experimental economics. JEL codes: H26, C91. 


\title{
Who Responds? Disentangling the Effects of Audits on Individual Tax Compliance Behavior
}

\author{
James Alm ${ }^{1}$, Ali Enami², and Michael McKee ${ }^{3}$
}

\begin{abstract}
How does individual tax compliance respond to a change in the audit rate? Most all empirical evidence suggests that an increase in the audit rate increases the compliance rate, a result that is also consistent with standard theoretical analysis of the individual compliance decision. However, this empirical evidence is typically based on estimating an average response across all taxpayers, and an average response may conceal much heterogeneity in individual responses. This paper collects individuallevel data from identical laboratory experiments across five separate studies with a total of 278 student subjects that generated 8340 individual observations, in which only audit rates are varied, in order to disentangle individual responses to audit rate changes. As with most previous empirical work, our results indicate that the average response across all taxpayers is to increase (decrease) compliance when audit rates increase (decrease). However, this average response conceals enormous heterogeneity in individual responses. When the individual responses are examined in more detail, our data show that many individuals do in fact respond to higher (lower) audit rates by increasing (decreasing) their compliance. However, these individuals represent only about 2/3 of all subjects. In fact, our data also show that many individuals do not respond at all to audit rate changes. Surprisingly, our data further show that some individuals actually decrease their compliance when audit rates increase, and vice versa. All of these different individual responses indicate that government policy interventions must consider the "full house" of individual behaviors when devising appropriate policies.
\end{abstract}

JEL H26, C91

Keywords Tax evasion, Tax compliance, Behavioral economics, Experimental economics

\section{Acknowledgments}

We thank Richard Cebula, Katherine Virgo, and an anonymous referee for many helpful comments and suggestions.

\section{Declarations}

Several of the studies used in this paper received partial funding from Internal Revenue Service grants; the views expressed here are those of the authors, and do not reflect the opinions of the Internal Revenue Service. The authors declare no conflicts of interest. All data and code used in this paper are available upon request.

${ }^{1}$ Department of Economics, Tulane University, New Orleans, LA 70118, USA (jalm@tulane.edu)

${ }^{2}$ Department of Economics, The University of Akron, Akron, OH 44325, USA (aenami@uakron.edu

${ }^{3}$ Department of Economics, Walker College of Business, Appalachian State University, Boone, NC 28608, USA (mckeemj@appstate.edu) 


\section{Introduction}

How does individual tax compliance respond to a change in the audit rate? Most all empirical evidence suggests that an increase in the audit rate increases the compliance rate, with estimated reported income-audit rate elasticities generally finding a significant positive elasticity, often between 0.2 and 0.4 and occasionally larger. ${ }^{1}$ This empirical result is consistent with the standard economics-of-crime model of individual tax compliance behavior pioneered by Allingham and Sandmo (1972), which assumes that that an individual views tax compliance purely as a gamble and which concludes that an individual pays taxes because of the fear of being caught and penalized.

However, as we discuss in more detail later, there are numerous reasons for some caution in concluding that either the theoretical or the empirical findings will apply in all settings. Theoretical work often ignores a range of individual motivations, many of which weaken and may even reverse the connection between audits and compliance. Of specific relevance for our paper here, empirical work on tax compliance is plagued by difficulties in finding detailed and reliable information on individual compliance choices, information that clearly identifies the causal effects of policy interventions on individual behavior. Even when such data are available, the resulting estimates are typically based on an average response across all taxpayers, and an average response may conceal much heterogeneity in individual responses.

In this study, we collect individual-level data from identical laboratory experiments across five separate studies with student subjects in which only audit rates are varied, in order to disentangle individual responses to audit rate changes. Our measures of compliance are accurate and unambiguous measures of individual choices. These measures are also derived in a setting that controls explicitly for extraneous influences on individual behavior, which allows us to identify the

\footnotetext{
${ }^{1}$ For recent surveys of this large and still growing literature, see Alm (2019) and Slemrod (2019).
} 
impact of a change in single policy variable (e.g., the audit rate) on the outcome of interest (e.g., individual compliance). There are obvious reasons for caution in using data from laboratory experiments. However, the laboratory offers an opportunity to investigate, in a controlled environment, individual responses to audit rate changes, and to disentangle individual responses from average responses.

As with most previous empirical work, our results indicate that the average response across all taxpayers is to increase (decrease) compliance when audit rates increase (decrease), with an estimated reported income-audit rate elasticity comparable to previous empirical estimates. However, our data also indicate the presence of enormous heterogeneity in individual responses. Many individuals do in fact respond to an increase (decrease) in the audit rate by increasing (decreasing) their compliance rate. However, these individuals represent only about $2 / 3$ of all subjects. In fact, our data also show that many individuals do not respond at all to audit rate changes, roughly $1 / 6$ of all subjects. Surprisingly, our data further show that about $1 / 6$ of all subjects actually decrease their compliance when audit rates increase, and vice versa. Indeed, the average estimated response across all taxpayers is driven largely by those individuals who respond to a higher (lower) audit rate by reporting more (less) income, and, when we focus only on the individuals who respond "predictably" to audits, we estimate substantially larger responses to audits. These individual data also provide evidence consistent with the so-called bomb crater effect of tax audits. These different individual responses are consistent with some theories of individual behavior that go beyond the standard economics-of-crime model of behavior to incorporate other motivations for individuals. Overall, our empirical results suggest that government policy interventions - in compliance and beyond - must consider the "full house" of individual behaviors when devising appropriate policies. 


\section{Theoretical and Empirical Work on Income Tax Compliance}

\section{The Theory of Income Tax Compliance}

The basic theoretical model used in nearly all research on tax compliance starts with the work of Becker (1968) and his economics-of-crime model, as first applied to tax compliance by Allingham and Sandmo (1972). Here a rational individual is viewed as maximizing the expected utility of the tax evasion gamble (or lottery), weighing the benefits of successful cheating against the risky prospect of detection and punishment. The standard conclusion from this approach is that an individual pays taxes because he or she is afraid of getting caught and penalized if he or she does not report all income. ${ }^{2}$

This economics-of-crime approach therefore concludes that compliance depends upon enforcement. Indeed, it is essential to recognize that this approach concludes that an individual pays taxes because - and only because - of the economic consequences of detection and punishment. This is an important insight, with the obvious implication that the government can encourage greater tax compliance by increasing audit rates.

However, there are numerous reasons for some caution in concluding that these theoretical results will apply in all settings. The economics-of-crime model omits many potentially relevant factors, like employer withholding, third-party information reporting, labor supply choices, progressive tax systems, systematic audit selection rules, complicated and uncertain tax obligations, the use of paid preparers, and the like. Of particular relevance, the underlying assumptions of the economics-of-crime approach may not be accurate representations of individual behavior: that individuals are purely rational, that they have unlimited will-power, and that they are motivated entirely by narrowly defined and individually based financial considerations. All of

\footnotetext{
${ }^{2}$ Again, see especially Alm (2019) and Slemrod (2019) for recent surveys of the tax compliance literature.
} 
these assumptions have been increasingly questioned under the general rubric of "behavioral economics". Of special relevance here, in models informed by alternative behavioral economics considerations, the clear-cut comparative statics response to higher audit rates becomes weaker, in large part because these alternative models assume an array of other plausible motivations for "why people pay taxes". ${ }^{3}$ Individuals may be motivated by the way in which the compliance decision is framed (e.g., as a loss versus a gain); they may misperceive the true costs of their actions (e.g., overweighting or underweighting of audit rates); they may have difficulty making all of the computations due to complexity or uncertainty; and they may be motivated by a wide range of factors, including self-interest (narrowly defined) but also by notions of fairness, altruism, reciprocity, empathy, sympathy, trust, guilt, shame, morality, alienation, patriotism, social customs, social norms, tax morale, intrinsic motivation, and many other objectives that often have their origin in group considerations. All of these alternative motivations reduce the potential impact of audit rates, and in some theoretical models they may even reverse their effect, if more audits crowd out the intrinsic motivation to pay taxes.

\section{Empirical Evidence}

Conducting empirical research on tax compliance is notoriously difficult (Slemrod and Weber 2012). Hard, accurate, and reliable evidence on individual tax compliance is very hard to find, for obvious reasons. After all, tax evasion is illegal, and individuals have strong incentives to conceal their cheating. Even so, researchers have been increasingly creative in finding data to examine evasion.

The most accurate source of information on individual compliance is based on direct measurement of evasion via actual audits of individual returns, as with the Taxpayer Compliance

\footnotetext{
${ }^{3}$ See Hashimzade et al. (2013) for a comprehensive survey of these many behavioral economics approaches.
} 
Measurement Program (TCMP) or the National Research Program (NRP) of the U.S. Internal Revenue Service (IRS). Here detailed line-by-line audits of individual tax returns by IRS auditors yield an estimate of the taxpayer's "true" income, which when compared to actual reported items allows the IRS to calculate measures of income tax evasion (e.g. the tax gap). More indirect methods look for traces of evasion behavior that are left in various indicators (e.g., currency, electricity consumption, labor force participation) that can be measured, so that evasion is not measured directly but rather indirectly via these measurable traces. Some researchers have used measures of reported income from individual tax returns as a proxy for evasion, on the assumption that one's total income must be divided between (observable) reported income and (unobservable) unreported income. Some have used consumption-based or tax deduction-based measures as an indicator of tax evasion. There are also examples of even more novel approaches that estimate specific forms of evasion from original sources (e.g., information on discarded cigarette packs to measure tax evasion of a jurisdiction's cigarette taxes, information on commuter tax allowances to estimate fraudulent claims for these allowances, or information on internet purchases to estimate evasion of sales taxes).

Somewhere between direct and indirect methods lies the use of administrative data, or data collected by government departments and other organizations for the purposes of registration, transactions, and record keeping. These data do not typically have direct measures of tax evasion, but they may be linked to direct (e.g., tax audit) information.

However, researchers have become increasingly skeptical about the ability of most all forms of naturally occurring field data, even when generated by direct methods, to achieve identification of the causal effects of policies. The many indirect approaches exhibit even more significant identification problems, given their often aggregate nature. 
In part because of concerns with naturally occurring field data, researchers have increasingly employed controlled field experiments (or randomized controlled trials, RCTs). In a typical controlled field experiment, a treatment sample of individuals receives a message (e.g., a letter or an electronic notification) telling them some policy-relevant information (e.g., "Your tax return will be closely examined", "Most people pay their taxes", "Paying taxes helps others", “Taxes provide for public services"). A control sample of individuals receives a neutral message. The impact of the policy innovation is then examined by a simple comparison of the treatment group compliance with the control group compliance. To date most controlled field experiments have used this message approach. ${ }^{4}$

These controlled field experiments have a number of advantages. ${ }^{5}$ The most obvious is their ability to identify causal factors in the compliance decision; that is, they have a high degree of internal validity. They also generate their own observable data on individual choices, they can be replicated, and they use "real people". Even so, they seldom generate direct measures of evasion, they can be expensive, there are significant limits to the causal factors that can be examined, and they generally represent only one-time interventions.

Given these many limitations, all of this empirical evidence is considerably more problematic than it appears. In large part because of these limitations, researchers have often turned to laboratory experiments in compliance research. We discuss the use and the design of our laboratory experiments in the next section, including the specific design of the laboratory experiments that we utilize in this paper.

\footnotetext{
${ }^{4}$ For one of the first examples of the use of controlled field experiments in tax compliance work, see Blumenthal et al. (2001). For a recent example, see Hallsworth et al. (2017).

${ }^{5}$ See Hallsworth (2014) for a survey of the use of controlled field experiments in tax compliance research.
} 


\section{Design of Laboratory Experiments ${ }^{6}$}

The basic design of most compliance experiments is similar, and is meant to capture the parallelism necessary to generalize experimental results beyond the laboratory (Smith 1982; Plott 1987). Human subjects in a controlled laboratory are told that they should feel free to make as much income as possible. At the beginning of each round of the experiment, each subject earns (or is given) and must decide how much income to report. Taxes are paid at some rate on all reported, but not on underreported, income. However, underreporting is discovered with some probability, and the subject must then pay a fine on unpaid taxes. This process is repeated for a given number of rounds. At the completion of the experiment, each subject is paid an amount that depends upon his or her performance during the experiment. Into this microeconomic system, various policy changes can be introduced one at a time, such as changes in audit probabilities or audit rules, in penalty rates, in tax rates, in public good provision, and in any other relevant institutions. To date, laboratory experiments have examined virtually all factors that have been suggested as determinants of what motivates tax compliance. Our experiments focus on changes in audit rates.

Laboratory experiments seem particularly well-suited for the study of many aspects of the taxpayer reporting decision. They generate direct measures of evasion under different settings in which there is control over extraneous influences, they are relatively inexpensive, they can be easily replicated, and they have a high degree of internal validity. However, laboratory experiments are sometimes viewed with suspicion. ${ }^{7}$ The most common criticism is that the student subjects typically used in experiments may not be representative of taxpayers. As a result, there is a concern that experimental results on policy innovations that rely upon student subjects cannot

\footnotetext{
${ }^{6}$ See Mascagni for a survey of the use of laboratory (and field) experiments in tax compliance research.

${ }^{7}$ See Levitt and List (2007) for a general critique of laboratory experiments. For robust responses to this critique, see Falk and Heckman (2009), Camerer (2015), Harrison et al. (2015), and Kessler and Vesterlund (2015).
} 
generalize to the population; that is, the external validity of laboratory experiments is sometimes questioned.

Still, it seems likely that the results can contribute to our understanding of the compliance puzzle, in part because there is much accumulating evidence that there is little difference between student and nonstudent responses. ${ }^{8}$ Also, there is now a large literature that argues convincingly that experimental methods can contribute significantly to policy debates, as long as some conditions are met: the payoffs to subjects must be salient, better subject decisions yield higher subject payoffs, decision costs must be commensurate with the payoffs, and the experimental setting must capture the essential properties of the naturally occurring environment that is the subject of investigation. These conditions are met with all of the experiments that we use here.

All experiments for which we collected data followed the same basic and identical design, a design that was consistent with the theoretical model and with the basic experimental design discussed above. Student subjects earned income, they paid taxes on income voluntarily reported, they faced a probability of audit, and they paid a penalty on taxes not paid if they were detected cheating. Into this setting we introduced changes in audit rates only, holding constant all other factors. ${ }^{9}$

Subjects were volunteers, recruited from undergraduate classes at a large state university, and they had no prior experience with the experiments. ${ }^{10}$ Upon arrival at the laboratory, each subject was assigned to a computer station and was also assigned an identification number. The lab server assigned subjects to groups of various sizes, in which they remained for the entire experiment. Basic instructions were provided via hardcopy while the main instructions were provided via a

\footnotetext{
${ }^{8}$ See Alm et al. (2015) for evidence on the external validity of tax compliance experiments. They find that student and non-student behaviors are similar.

${ }^{9}$ Representative instructions and screen shots of the experimental instructions are available upon request.

${ }^{10}$ Demographic information collected from subjects after the completion of the experiments indicate that approximately one-half of the subjects across all studies completed their own individual income tax returns, while the other one-half of subjects were claimed as dependents on their parents' tax returns. Other demographic information (e.g., age, gender, academic major) was also largely the same across all studies.
} 
series of computer screen images. After several practice rounds were completed, any final procedural questions were answered. Participants were not allowed to communicate with one another during the session except when allowed via the computer interface as a treatment. They were not told the exact duration of the experimental session, which was predetermined to last for at least 30 real rounds. Subjects were also told that all accumulated tokens would be redeemed in cash at the end of the experiment at a given exchange rate. Sessions took on average 90 minutes to complete. Participant earnings ranged from $\$ 19$ to $\$ 37$, depending upon task earnings, reporting behavior, and audit experience. Subjects were told that payments would be made in private at the end of the session and that all responses would be anonymous. The person conducting the experiment did not interact with the subjects once the actual experiment begins and the subjects were informed that their decisions would not be observed by the person conducting the session. Taken together, these experimental procedures implemented the properties of a double-blind design.

At the beginning of a round, each subject earned income from a simple matching task, and this income was known only to the subject. The subject then decided how much of this income to report. Reported income was taxed at an announced rate. Unreported income was not taxed; however, the subject faced some probability of audit, at which point all unreported income for the current round was detected and a fine equal to an announced multiple of unpaid taxes was imposed. The audit selection was determined for each subject by the use of a virtual computerized bingo cage, in which subjects were shown an animated (computerized) representation of a bucket from which a draw was made. In this computerized bucket there were balls (either blue or white) with a white ball signifying no audit and a blue ball denoting an audit. Each taxpayer was audited independently. The balls "bounced" in the bucket, and then a door opened and a ball exited the bucket through 
this door, with the color of the ball indicating whether the subject was audited. The audit applied only to the current period declarations, not to previous or future periods. The computer automatically deducted any additional taxes and penalties (if any are owed) from a subject's account. After the audit process was completed, each subject was shown a new screen that provided the earnings and audit outcome summary for the round.

The experimental setting in all sessions was very contextual, in order to provide the necessary degree of parallelism to the naturally occurring world that is crucial for the general applicability of experimental results (Smith 1982; Plott 1987). The experimental interface and instructions used tax language throughout, the subjects disclosed their tax liability in the same manner as on a typical tax form, there was a time limit on the reporting of income, and the subject was automatically audited if he or she failed to report on time.

We utilize data collected from five of our own experimental papers. These papers examined different aspects of the compliance decision, but all used the identical experimental design. One paper examined the effects of audits that did not discover all evasion (Alm and McKee 2006); another examined the effects of employer withholding (Alm et al. 2009a); and three examined the effects of different types of information dissemination (Alm et al. 2009b; Alm et al. 2010; Alm et al. 2016). We limit our data collection to those specific treatments across the various papers in which only the audit rate was varied, in order to focus specifically on how subjects respond to the policy variable (e.g., the audit rate) that has been the most frequently studied across the experimental literature and for which the theoretical prediction is most clear-cut. Specifically, we collected data from all of our experimental papers in which we varied the audit rate from 5 percent, to 10 percent, to 30 percent, and to 40 percent, in various combinations of increases and decreases, holding constant all other factors that 
may affect decisions (e.g., tax rates, penalty rates). ${ }^{11}$

Given that we have direct and accurate measures of individual compliance decisions, we are able to examine individual responses to the various changes in the audit rates. Our data therefore allow us to attribute any change in individual compliance behavior directly to the change in the audit rate. The next section presents our results.

\section{Results}

Overall, our data are based on 278 student subjects across the five separate experimental studies conducted at three large state universities. We observe each of the 278 subjects for 30 rounds, generating in total 8340 observations.

\section{Aggregate/Average Results}

On average, the compliance rate (or reported income / "true" income) across all subjects and all rounds is 48.15 percent, with the average audit rate across all rounds and all subjects equal to 20.01 percent. This overall average compliance rate of 48.15 percent varies significantly across the different audit rates. For an audit rate of 5 percent, the average compliance rate across all rounds and all subjects who faced the 5 percent audit rate is 34.79 percent; for an audit rate of 10 percent, the average compliance rate is 40.48 percent; for an audit rate of 30 percent, the average compliance rate is 55.45 percent; and for an audit rate of 40 percent, the average compliance rate across all rounds and all subjects who faced the 40 percent audit rate is 60.47 percent. It is clear the compliance increases with the audit rate as predicted by theory and as indicated by previous empirical work, although this increase is somewhat nonlinear as the audit rate increases.

\footnotetext{
${ }^{11}$ The tax rate is held constant in all of our data at 35 percent, and the penalty rate is also held constant at 50 percent (e.g., subjects who are audited and found to be noncompliant must pay unpaid taxes plus a penalty of 50 percent of unpaid taxes). There is no public good in any of the experiments that we utilize for this paper.
} 
This result is also demonstrated by simple regressions in which the average of each individual's compliance rate over the 15 rounds of a given audit rate is regressed on the audit rate for these rounds, using the "Full sample" of subjects (e.g., all subjects). See Table 1. The resulting estimated elasticity of reported income to the audit rate across all subjects and all rounds equals 0.35 , an estimate that is statistically significant at the 1 percent level and that is similar to existing estimates of the reported income-audit rate elasticity based both on laboratory experiments (Alm et al. 1992) and on naturally occurring field data (Alm and Yunus 2009). This estimate is not affected by including in alternative (unreported) specifications individual subject demographic variables or average subject income over these rounds. However, this estimate is affected by estimating separately responses to increases versus decreases in the audit rates, as demonstrated by the results in Table 1. Of some interest, subjects generally respond more to a decrease in the audit rate than to an increase in the audit rate. For example, the estimated elasticity for a decrease in the audit rate from 40 percent to 5 percent is 0.64 ; the elasticity for an increase in the audit rate from 5 percent to 40 percent is only 0.08 . Similar results are found for the 10 percent and 30 percent audit rate changes.

\section{[Place Table 1 about here]}

\section{Individual Results}

However, this average behavior and average response obscure much individual heterogeneity. First, the frequency distribution of individual compliance rates demonstrates a wide range of compliance, varying from 0 compliance to 100 percent compliance, with many individuals also choosing intermediate levels of compliance. Indeed, there is substantial evidence of all-or-none behavior, a result that is commonly found in experimental studies. See Figure 1 for the frequency distribution of individual compliance rates across all audit rates; similar all-or-none behavior is 
demonstrated by separate frequency distributions for the 4 different audit rates (e.g., 5 percent, 10 percent, 30 percent, and 40 percent).

\section{[Place Figure 1 about here]}

Second, when we examine individual responses to audit rate changes, we see quite varied behavior (Table 2). About $2 / 3$ of the subjects respond to a higher (lower) audit rate by reporting more (less) income, as predicted by theory; we designate these subjects as the "'Proper response sample" because they responded to an increase (decrease) in the audit rate by increasing (decreasing) their compliance rate. Indeed, estimating the reported income - audit rate elasticity with only the "'Proper' response sample" generates an elasticity that is nearly double the elasticity estimated with the "Full sample", as shown in Table 1 . However, roughly $1 / 6$ of all subjects reported about the same level of income when the audit rate changed, whether increasing or decreasing, although this varies by the type of audit rate change (the "No response sample"). Further and strikingly, as much as 1/6 of the subjects actually reported lower (higher) income when

audit rates increased (decreased), which we designate the "'Improper' response sample". All of these 3 different samples exhibit responses that also vary by the type of audit rate change, as demonstrated by Table 2. Keep in mind that these results were generated in a controlled setting in which the only causal factor that varied was the audit rate.

\section{[Place Table 2 about here]}

Our data also allow us to examine the individual response to an audit in the round immediately following an audit. Here we find that 38.2 percent of all subjects who are audited in a round respond in the next round by increasing their compliance. However, 46.9 percent respond by decreasing their compliance, and 14.9 percent do not change significantly their behavior. Further, these differential responses depend largely on whether the audit discovered compliant 
versus noncompliant behavior. For those audited subjects who were largely compliant (e.g., a compliance rate over 90 percent), the dominant response to an audit was to reduce their compliance rate. 67.3 percent of audited and compliant subjects reduced the compliance rate in the immediately following round, 22.2 percent increased the compliance rate, and 10.5 percent did not change the compliance rate. In contrast, audited subjects who were largely non-compliant (e.g., a compliance rate less than 90 percent) typically responded to an audit by increasing the compliance rate: 61.9 percent increased the compliance rate after an audit, 30.4 percent decreased the compliance rate, and 7.7 percent did not change the compliance rate. These results are largely consistent with the so-called bomb-crater effect, in which an audit tends to lower post-audit compliance (Mittone 2006). They are also consistent with recent studies that have found that the post-audit experience of taxpayers depends largely upon whether the audit found that taxpayers were compliant or noncompliant (Gemmell and Ratto 2012; DeBacker et al. 2018; Beer et al. 2020).

In short, there is enormous variation in individual behaviors in response to any change in the audit rate. The average treatment effect clearly demonstrates the standard and expected individual response of compliance to changes in the audit rate. However, the average treatment effect is not the only, or even the most interesting, measure of responsiveness.

\section{Conclusions}

All of this evidence indicates that there is certainly some truth to the Allingham and Sandmo (1972) model of compliance, but that its reliance on standard assumptions limits its actual empirical relevance in many settings. In particular, we believe that our empirical evidence indicates that some individuals are indeed motivated by narrowly defined, and individually based, financial considerations like audits. However, some individuals are likely to be motivated by non-financial 
considerations, some may be motivated by social considerations, and still others may be motivated by information and by the ways in which they process this information. Overall, we believe that the evidence is overwhelming that there is great heterogeneity across individuals; that is, individuals cannot be represented by a single representative agent, as is often assumed, but must be considered a collection of different segments.

This last conclusion - on individual heterogeneity - is especially important. Put differently, there is no average individual who responds predictably and reliably to all policies. People are complicated, motivated by many different factors, and responsive (if at all) in many different ways. In this regard, Gould (1996) emphasizes that it is grossly misleading to represent a complex system by a single, so-called representative agent, who behaves in some average or typical way. Instead, most systems have incredible variety - a "full house" of individual behaviors - and the proper understanding of any system requires recognition of this basic fact. Indeed, Gould (1996) argues that the ways in which a system changes over time are attributable largely to changes in the amount of variation within the system, rather than to changes in some largely meaningless average behavior across its individual members.

As emphasized earlier, there are reasons for caution in the use of and generalization from these estimates. Still, it seems likely that the results can contribute to our understanding of the compliance puzzle, at least in part because of the well-known limitations of most all empirical approaches to tax compliance. Laboratory experiments are not immune to these criticisms, but other approaches are also subject to many - indeed perhaps more - of these limitations.

In sum, we believe that our findings suggest that research needs to recognize that any theoretical and empirical work on tax compliance must recognize this "full house" of individual behaviors. We also believe that this "full house" of behaviors must be recognized in devising a 
"full house" of policy tools, whether in compliance or in other public policy arenas.

\section{References}

Allingham, M. G., \& Sandmo, A. (1972). Income tax evasion: A theoretical analysis. Journal of Public Economics, 1 (3-4), 323-338.

Alm, J. (2019). What motivates tax compliance? Journal of Economic Surveys, 33 (2), 353-388.

Alm, J., Bloomquist, K. M., \& McKee, M. (2015). On the external validity of laboratory tax compliance experiments. Economic Inquiry, 53 (2), 1170-1186.

Alm, J., Bruner, D., \& McKee, M. (2016). Honesty and dishonesty in taxpayer communications in an enforcement regime. Journal of Economic Psychology, 56, 85-96.

Alm, J., Cherry, T. L., Jones, M., \& McKee, M. (2010). Taxpayer information assistance services and tax reporting behavior. Journal of Economic Psychology, 31 (4), 577-586.

Alm, J., Deskins, J., \& McKee, M. (2009a). Do individuals comply on income not reported by their employer? Public Finance Review, 37 (2), 120-141.

Alm, J., Jackson, B. R., \& McKee, M. (1992). Estimating the determinants of taxpayer compliance with experimental data. National Tax Journal, 45 (1), 107-114.

Alm, J., Jackson, B. R., \& McKee, M. (2009b). Getting the word out: Increased enforcement, audit information dissemination, and compliance behavior. Journal of Public Economics, 93 (34), 60-84.

Alm, J., \& McKee, M. (2006). Audit certainty, audit productivity, and taxpayer compliance. National Tax Journal, 59 (4), 801-816.

Alm, J., \& Yunus, M. (2009). Spatiality and persistence in U.S. individual income tax compliance. National Tax Journal, 62 (1), 101-124.

Becker, G. S. (1968). Crime and punishment - An economic approach. The Journal of Political Economy, 76 (2), 169-217.

Beer, S., Kasper, M., Kirchler, E., \& Erard, B. (2020). Do audits deter future noncompliance? Evidence on self-employed taxpayers. CESifo Economic Studies, forthcoming.

Blumenthal, M., Christian, C., \& Slemrod, J. (2001). Do normative appeals affect tax compliance? Evidence from a controlled field experiment in Minnesota. National Tax Journal, 54 (1), $125-128$.

Camerer, C. F. (2015). The promise and success of lab-field generalizability in experimental economics: A reply to Levitt and List. In G. R. Frechette and A. Schotter (eds.), The Methods of Modern Experimental Economics. New York, NY: Oxford University Press, Chapter 14, 249-295.

DeBacker, J., Heim, B. T., Tran, A., \& Yuskavage, A. (2018). Once bitten, twice shy? The lasting impact of IRS audits on individual tax reporting. The Journal of Law and Economics, 61 (1), 1-35.

Falk, A., \& Heckman, J. J. (2009). Lab experiments are a major source of knowledge in the social sciences. Science, 326 (5952), 535-538.

Gemmell, N., \& Ratto, M. (2012). Behavioral responses to taxpayer audits: Evidence from random taxpayer inquiries. National Tax Journal, 65 (1), 33-58.

Gould, S. J. (1996). Full House: The Spread of Excellence from Plato to Darwin. New York, NY: Harmony Books. 
Hallsworth, M. (2014). The use of field experiments to increase tax compliance. Oxford Review of Economic Policy, 30 (4), 658-679.

Hallsworth, M., List, J. A., Metcalfe, R. D., \& Vlaev, I. (2017). The behavioralist as tax collector: Using natural field experiments to enhance tax compliance. Journal of Public Economics, $148,14-31$

Harrison, G. W., Lau, M., \& Rutström, E. E. (2015). Theory, experimental design and econometrics are complementary (and so are lab and field experiments). In G. R. Frechette and A. Schotter (eds.), The Methods of Modern Experimental Economics. New York, NY: Oxford University Press, Chapter 15, 296-338.

Hashimzade, N., Myles, G. D., \& Tran-Nam, B. (2013). Applications of behavioural economics to tax evasion. Journal of Economic Surveys, 27 (5), 941-977.

Kessler, J. B., \& Vesterlund, L. (2015). The external validity of laboratory experiments: The misleading emphasis on quantitative effects. In G. R. Frechette and A. Schotter (eds.),The Methods of Modern Experimental Economics. New York, NY: Oxford University Press, Chapter 18, 391-406.

Levitt, S. D., \& List, J. A. (2007). What do laboratory experiments measuring social preferences reveal about the real world? The Journal of Economic Perspectives, 21 (2), 153-174.

Mascagni, G. (2018). From the lab to the field: A review of tax experiments. Journal of Economic Surveys, 32 (2), 273-301.

Mittone, L. (2006). Dynamic behavior in tax evasion: An experimental approach. The Journal of Socio-Economics, 35 (5), 813-835.

Plott, C. R. (1987). Dimensions of parallelism: Some policy applications of experimental methods. In A. E. Roth (ed.), Laboratory Experimentation in Economics: Six Points of View. New York, NY: Cambridge University Press, 193-219.

Slemrod, J. (2019). Tax compliance and enforcement. The Journal of Economic Literature, 57 (4), 904-954.

Slemrod, J., \& Weber, C. (2012). Evidence of the invisible: Toward a credibility revolution in the empirical analysis of tax evasion and the informal economy. International Tax and Public Finance, 19 (1), 25-53.

Smith, V. L. (1982). Microeconomic systems as an experimental science. The American Economic Review, 72 (5), 923-955. 